\title{
From DNA to emerging technologies: innovative quality markers
}

\begin{abstract}
The recognition of dairy products as safe and authentic is considered of paramount importance given the economic value that this sector generates. Quality requirements of a product could also be related to its origin, conditions of storage or to the absence any fraudulent practice. To this purpose, some markers have been indicated to investigate a distinctive trait of quality. These markers may be of different nature (molecular, biochemical or physical) and they proved to be useful and reliable tools in assessing food quality.
\end{abstract}

Keywords: quality, markers, traceability, dairy products
Volume 2 Issue I - 2015

\author{
Flavio Tidona \\ Council for Research and Experimentation in Agriculture, Italy \\ Correspondence: Flavio Tidona, Council for Research and \\ Experimentation in Agriculture-Research Center for Forage \\ Production and dairy (CRA-FLC)-Lodi, Italy, Tel +39-338 104 \\ 235I,Email flaviotido@hotmail.it
}

Received: October 24, 2014 | Published: January 09, 2015
Abbreviations: UPC, universal product code; BOLD, barcode of life database; GMO, genetically modified organisms; MS, mass spectrometry; UHT, ultra-high temperature; NIR, near-infrared; MIR, mid-infrared; RFID, radio frequency identification; QR, quick response

\section{Introduction}

Safety standards of food products, in particular in developed countries, have been progressively improved due to the increased national regulations, which are mandatory, together with voluntary certifications of quality adopted by a growing number of companies. Codex standards ${ }^{1}$ established that the labels of food shall not be false, misleading or deceptive, in order to promote fair trading and protect both consumers and fair producers. Nevertheless, these systems are not infallible nor provide all the guarantees that the end consumers might need. Besides the official controls managed by the competent authority, some innovative analytical tools have been developed to investigate, a specific quality requirement, such as the effective animal species of origin, the geographical origin of a product or its proper storage. To this regard, food authenticity can be assessed at the DNA level or may be related to chemical compounds, thus it is possible to distinguish molecular, biochemical or physical markers, which are briefly discussed.

\section{Molecular markers}

In the dairy field, a common fraud is the addition of a milk coming from a different species than the one declared. Cow's milk is usually considered the principal foreign milk, since it is overabundant compared to the milk of other species and it has a lower price. Whether it is caused by an illegal behavior or by an accidental contamination, there is the need to provide the consumers accurate guarantees not only for a commercial compliance but also to avoid medical implications. This is the case of hypoallergenic milks, as donkey or goat milk, mixed with cow's milk which is commonly recognized in sensitive people as a potential source of an atopic disease, associated with a broad spectrum of IgE-mediated reactions. ${ }^{2}$ The methods that efficiently allow to identify a species generally involve molecular markers, DNA-based. The lack of standard DNA sequences, universally recognized, was traditionally the main limit of a massive application of these markers. Yet, ${ }^{3}$ developed an identification system based on the analysis of the variability within a standard region of the genome. This region was called DNA barcoding which figuratively refers to the univocal product identification of the Universal Product Code (UPC). An efficient application of this method relies on the availability of an international platform, BOLD (Barcode of life database), collecting DNA barcodes to create a reference library for all living species. ${ }^{4}$ Several PCR-based methods have been developed for authenticity assessment of dairy products, targeting $\beta$-casein gene, cytochrome b or $12 \mathrm{~S}$ rRNA. ${ }^{5}$ Despite PCR methods allow to amplify small concentration of DNA, even traces, food processing may cause DNA degradation. This limit may be partially reduced using short sequences, named mini barcodes, although they may not be able to discriminate closely related species. ${ }^{6}$

\section{Biochemical markers}

Milk contains an array of non-redundant proteins which can be exploited to configure differential proteomic profiles, enabling to distinguish milk proteins from different mammals. Proteomic approaches have been successfully applied in the quality control and food safety, detecting toxins produced by food-contaminating pathogens such as Clostridium difficile, ${ }^{7}$ allergens or genetically modified organisms (GMO). ${ }^{8}$ Advances in mass spectrometry (MS) techniques increased sensitivity with detection limits lower than $1 \mathrm{ppm}$. Moreover, the analysis of peptides as biochemical markers is advantageous when highly processed food matrices are investigated, given the higher resistance of peptides compared to DNA. MS-based techniques were capable to determine bovine caseins in water buffalo mozzarella cheese ${ }^{9}$ and to discriminate also the cheeses obtained from the milk of two different breeds of Italian sheeps (Laticauda and Bagnolese) due to a specific fragment of as 1 -casein. ${ }^{10}$

\section{Chemical and physical markers}

During food processing or storage, a wide variety of metabolites is generated or modified, and these compounds may affect the quality (texture, flavour, odour, colour and shelf life) or the nutritional value (vitamins, antioxidants, and nutrients) of a product. Therefore, besides genomics and proteomics, the science of metabolomics is gaining great importance to evaluate the effects of microbial growth on food quality or to measure the action of a technological treatment. ${ }^{11}$ Ultrahigh temperature (UHT) treatments may cause, for instance, alterative 
processes on milk proteins, thus reducing their biological value. Although there are no maximum limits, excessive treatments give rise to some molecules (reaction by-products) which are useful markers to estimate thermal damages. Furosine, lactulose, and galactosyl$\beta$-pyranone are among the most suitable molecules investigated to evaluate the severity of the heat treatment. ${ }^{12}$ Similarly, these markers may also detect frauds such as the addition of reconstituting powder milk to UHT milk, analyzing the furosine/lactulose ratio. ${ }^{13}$ The presence of lysine-alanine is generally related to the use of caseinates in cheeses. ${ }^{14}$

Near-infrared (NIR) and mid-infrared (MIR) spectroscopy was tested to evaluate the effective shelf life of perishable products, such as soft cheeses. This technique provides a composition profile of a given product which is monitored in time and, applying a suitable mathematical model, the real state of the product can be predicted. ${ }^{15}$ Another approach to evaluate the shelf life was also performed by means of the electronic nose, which analyzes all the volatile components of a sample, providing a "fingerprinting" of the aromatic profile. ${ }^{16}$ This is particularly important for a fresh cheese, whose sensorial profile may dramatically drop, given its high enzymatic activity and microbial growth.

In addition, the ratio of the stable isotopes of carbon, oxygen and hydrogen $\left({ }^{13} \mathrm{C} /{ }^{12} \mathrm{C},{ }^{15} \mathrm{~N} /{ }^{14} \mathrm{~N},{ }^{18} \mathrm{O} /{ }^{16} \mathrm{O}\right.$ and $\left.{ }^{2} \mathrm{H} /{ }^{1} \mathrm{H}\right)$ found in milk, strictly depends on the feeding and water administered to the animals. In particular, ${ }^{13} \mathrm{C}$ isotopes are more abundant in corn and sugar cane whereas the relative abundance of ${ }^{18} \mathrm{O}$ e ${ }^{2} \mathrm{H}$ isotopes affects the water on the base of the latitude, altitude and distance from the sea. ${ }^{17}$ Thus these physical markers are useful to track the geographical origin of a product when the food quality is linked with a characteristic territory.

\section{Emerging technologies}

Overall food quality derives from the quality of raw materials but it is also affected by the processing, proper storage (especially for cold chain products) and even by transportation conditions. In a dairy product, these elements can be recorded by means of radio frequency identification (RFID) technology, collecting all the information for traceability, from the milk used (place and day of milking), to the temperature of final transport. The data are merged on a QR (Quick Response) code and made available to the consumer. ${ }^{18}$ The role of packaging (active and intelligent packaging) is also showing multifunctional tasks, interacting with the product or the environment and providing indication of its current quality. Immediate visual information can be shown by indicators through colorimetric changes, an increase in color intensity or diffusion of a dye. Different indicators can be integrated in the food packaging such as gas, freshness and time-temperature indicators or thermochromic inks which can cause reversible color changes depending on temperature. ${ }^{19}$

In the field of chemical sensors, recent technological breakthroughs will design a new generation of sensors which are requested to be small, fast, with low detection limits and selective. Innovative and user friendly biosensors are being developed, using nanostructures between 1 and $100 \mathrm{~nm}$, able to assess the state-of-the-art food quality. Depending on the application, the nanosensors may work on different types of immunoassays, monitoring various contaminations like pathogenic microorganisms, mycotoxnins or drug residues. A first fluorescent sensor (BODIPY ${ }^{\circledR}$ ) was recently developed for instant and quantitative milk fat determinations. ${ }^{20}$

\section{Conclusion}

Quality and safety requirements are a major concern for the dairy industries; therefore the use of specific markers may help both honest producers and end consumers to assess the authenticity of a product. Technological advances allow to predict rapid and accurate analysis which also will provide more comprehensive information to consumers.

\section{Acknowledgements}

None.

\section{Conflict of interest}

Author declares that there is no conflict of interest.

\section{References}

1. Codex Alimentarius. Labelling of Prepackaged Foods. CODEX STAN 1-1985. 1985

2. Lara-Villoslada F, Olivares M, Xaus J. The balance between caseins and whey proteins in cow's milk determines its allergenicity. J Dairy Sci. 2005;88(5):1654-1660.

3. Herbert PDN, Cywinska A, Ball SH, de Waard, et al. Biological identifications through DNA barcodes. Proceedings of the Royal Society B. 2003;270:313-321.

4. Ratnasingham S, Hebert PDN. BOLD: the barcode of life datasystem. Mol Ecol Notes. 2007;7(3):355-364.

5. Mafra I, Ferreira IM, Beatriz MP, et al. Food authentication by PCRbased methods. Eur Food Res Technol. 2008;227(3):649-665.

6. Galimberti A, De Mattia F, Losa A, et al. DNA barcoding as a new tool for food traceability. Food Res Int. 2013;50(1):55-63.

7. Moura H, Terilli RR, Woolfitt AR, et al. Proteomic analysis and label-free quantification of the large Clostridium difficile toxins. Int $J$ Proteomics. 2013.

8. D'alessandro A, Zolla L. Food Safety and Quality Control: Hints from Proteomics. Food Technol Biotechnol. 2012;50(3):275-285.

9. Cozzolino R, Passalacqua S, Salemi S, et al. Identification of adulteration in milk by matrix-assisted laser desorption/ionization time-of-flight mass spectrometry. J Mass Spectrom. 2002;36(9):1031-1037.

10. Di Luccia A, Picariello G, Trani A, et al. Occurrence of beta-casein fragments in cold-stored and curdled river buffalo (Bubalus bubalis L.) milk. J Dairy Sci. 2009;92(4):1319-1329.

11. Picariello G, Mamone G, Addeo F, et al. Novel mass spectrometrybased applications of the 'omic' sciences in food technology and biotechnology. Food Technol Biotechnol. 2012;50(3):286-305.

12. Mayer HK, Raba B, Meier J, et al. RP-HPLC analysis of furosine and acid-soluble $\beta$-lactoglobulin to assess the heat load of extended shelf life milk samples in Austria. Dairy Sci Technol. 2010;90(4):413-428.

13. Corzo N, Delgado T, Troyano E, et al. Ratio of lactulose to furosine as indicator of quality of commercial milks. J Food Protect. 1994;8:658-752.

14. Calabrese MG, Mamone G, Caira S, et al. Quantitation of lysinoalanine in dairy products by liquid chromatography-mass spectrometry with selective ion monitoring. Food Chem. 2009;116(3):799-805.

15. Cattaneo TMP, Giardina C, Sinelli N, et al. Application of FT-NIR and FT-IR spectroscopy to study the shelf-life of Crescenza cheese. Int Dairy J. 2005;15(6-9):693-700. 
16. Benedetti S, Sinelli N, Buratti S, et al. Shelf life of crescenza cheese as measured by electronic nose. J Dairy Sci. 2005;88(9):3044-3051.

17. Novelli E, Balzan S, Perini M, et al. Analytical employment of stable isotopes of carbon, nitrogen, oxygen and hydrogen for food authentication. Ital J Food Safety. 2011;1(1):2239-7132.

18. Abad E, Palacio F, Nuin M, et al. RFID smart tag for traceability and cold chain monitoring of foods: Demonstration in an intercontinental fresh fish logistic chain. J Food Eng. 2009;93(4):394-399.
19. Vanderroost $M$, Ragaert $P$, Devlieghere $F$, et al. Intelligent food packaging: The next generation. Trends Food Sci Tech. 2014;39(1):47-62.

20. Xu W, Bai J, Peng J, et al. Milk quality control: instant and quantitative milk fat determination with a BODIPY sensor-based fluorescence detector. Chem Commun(Camb). 2014;50(72):10398-10401. 